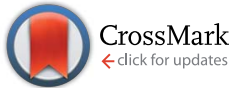

Cite this: RSC Adv., 2016, 6, 37994

DOI: $10.1039 / c 6 r a 90036 d$

www.rsc.org/advances

\section{Correction: Calcite precipitation from by-product red gypsum in aqueous carbonation process}

\author{
Omeid Rahmani, ${ }^{* a b}$ Mark Tyrer ${ }^{c}$ and Radzuan Junin ${ }^{a}$ \\ Correction for 'Calcite precipitation from by-product red gypsum in aqueous carbonation process' by \\ Omeid Rahmani et al., RSC Adv., 2014, 4, 45548-45557.
}

The authors regret that the reproduction of images from their previous work was not acknowledged in their article. Permission for the reproduction of images from O. Rahmani, R. Junin, M. Tyrer, R. Mohsin, Energy Fuels, 2014, 28, 5953-5958 (cited as ref. 11 in the original article) had been obtained from the publisher, but was not declared alongside the relevant figures.

The captions for Fig. 2 and 6 have therefore been revised to the following:

"Fig. 2 X-ray diffraction of bulk red gypsum sample. Reproduced with permission from ref. 11. Copyright 2014, American Chemical Society."

"Fig. 6 The effect of procedure variables (a) reaction temperature, (b) stirring rate, (c) liquid to solid ratio, and (d) particle size on conversion of $\mathrm{Ca}$ to $\mathrm{CaCO}_{3}$ in mineral carbonation process. Reproduced with permission from ref. 11. Copyright 2014, American Chemical Society."

The Royal Society of Chemistry apologises for these errors and any consequent inconvenience to authors and readers. 